\title{
PENGGUNAAN KATA BAKU DAN TIDAK BAKU DI KALANGAN MAHASISWA UNIVERSITAS PEMBANGUNAN NASIONAL “VETERAN” YOGYAKARTA
}

\author{
Via Setya Ningrum \\ Universitas Pembangunan Nasional "Veteran" Yogyakarta \\ Email: vianingrum123@gmail.com
}

\begin{abstract}
Language is the identity of a nation when interacting. Humans need language to communicate with people, or do other social activities. Indonesian is the language of unity, which means to be a liaison language between tribes in Indonesia. As a language of unity it must have a clear structure using standard words to be a good and correct language that is easy to understand. Students are people who often interact with other people of different ethnic groups. Therefore, students must have knowledge and understanding of standard words so that the communication process is not obstructed. However, today many students have low knowledge and understanding of standard words and are more interested in foreign words or slang words combined with Indonesian. Students as agents of change should use standard words in Indonesian so that our unity language can be maintained and sustainable and its existence is not shifted by foreign languages.
\end{abstract}

Keywords: standard words, non standard words, students

\begin{abstract}
Abstrak: Bahasa adalah identitas suatu bangsa ketika berinteraksi. Manusia membutuhkan bahasa untuk berkomunikasi dengan orang, atau melakukan kegiatan sosial yang lain. Bahasa Indonesia adalah bahasa persatuan yang artinya menjadi bahasa penghubung antar suku di Indonesia. Sebagai bahasa persatuan haruslah memiliki struktur yang jelas dengan menggunakan kata baku agar menjadi bahasa yang baik dan benar serta mudah dipahami. Mahasiswa adalah orang yang sering berinteraksi dengan orang lain yang berbeda suku. Oleh karena itu, mahasiswa harus memiliki pengetahuan serta pemahaman mengenai kata baku agar proses komunikasi tidak terhambat. Namun, sekarang ini banyak mahasiswa yang rendah pengetahuan serta pemahaman mengenai kata baku dan lebih tertarik dengan kata-kata asing atau kata gaul yang dipadukan dengan bahasa Indonesia. Mahasiswa sebagai agen perubahan harusnya menggunakan kata-kata baku dalam bahasa Indonesia agar bahasa persatuan kita bisa terus terjaga dan lestari serta keberadaannya tidak digeser oleh bahasa asing.
\end{abstract}

Kata Kunci: kata baku, kata tidak baku, mahasiswa

\section{PENDAHULUAN}

Bahasa Indonesia merupakan bahasa ibu yang artinya berasal dari tanah air Indonesia sendiri. Dahulu memang namanya bukan bahasa Indonesia, melainkan bahasa Melayu. Kemudian bahasa Melayu yang sudah lama digunakan oleh bangsa Indonesia serta tatanan bahasanya yang mudah diterima dan dipahami menjadikannya bahasa persatuan yang diikrarkan saat Sumpah Pemuda pada tanggal 28 Oktober 1928 dengan nama bahasa Indonesia. Bahasa Indonesia memiliki berbagai fungsi dan juga kedudukan yang menjadikannya sangat sakral dan dijunjung tinggi oleh bangsa Indonesia. Salah satu kedudukan bahasa 
Indonesia yaitu sebagai bahasa nasional. Bahasa Indonesia sebagai bahasa nasional mencerminkan nilai-nilai sosial budaya yang mendasari adanya rasa kebangsaan. Hal ini berarti bahasa Indonesia menyatukan banyaknya bahasa daerah antar suku di Indonesia sehingga terbentuk suatu kesatuan dan rasa kebangsaan. Oleh karena itu, bahasa Indonesia yang digunakan haruslah dengan kata-kata baku serta baik dan benar. Kata baku adalah kata yang digunakan telah sesuai dengan kaidah atau pedoman bahasa yang sudah ditentukan.

Dalam kehidupan ini, semua golongan masyarakat pasti menggunakan bahasa Indonesia untuk berkomunikasi dengan orang yang berbeda daerah atau berbeda latar belakang suku. Terutama remaja atau orang dewasa karena mereka lebih sering bertemu dengan orang lain. Seperti saat di sekolah, di kampus, di tempat kerja, dan lainnya. Namun terkadang bahasa yang digunakan tidak baku. Sehingga, kegiatan komunikasi antara pembicara dan pendengar akan terhambat akibat ada kata-kata yang tidak diketahui oleh salah satu pihak. Oleh karena itu, mempelajari serta memahami kata-kata baku sangat penting untuk dilakukan karena hal ini merupakan bagian mendasar dari sebuah bahasa sebagai alat pemersatu bangsa. Berdasarkan uraian yang telah dipaparkan diatas, Penulis akan membuat jurnal yang berjudul "Pemahaman Kata Baku dan Tidak Baku di Kalangan Mahasiswa Universitas Pembangunan Nasional “Veteran” Yogyakarta.”

\section{KATA BAKU DALAM BAHASA INDONESIA}

Mungkin semua orang sering sekali mendengar istilah kata baku. Akan tetapi, tidak semua orang tahu definisi dan hal-hal yang berkaitan dengan kata baku dan kata tidak baku. Kata baku merupakan sebuah kata yang digunakan sudah sesuai dengan pedoman atau kaidah bahasa yang sudah ditentukan. Dalam KBBI Edisi Keempat disebutkan pengertian baku adalah pokok, utama; tolok ukur yang berlaku untuk kuantitas dan kualitas yang ditetapkan berdasarkan kesepakatan; standar (Setiawati, Sulis, 2016:48). Sementara menurut Kosasih dan Hermawan (2012:83) kata baku adalah kata yang diucapkan atau ditulis oleh seseorang sesuai dengan kaidah atau pedoman yang dibakukan. Kaidah standar yang dimaksud dapat berupa pedoman ejaan (EYD), tata bahasa baku, dan kamus.

Kata baku umumnya sering dipakai pada kalimat resmi atau ragam bahasa baku, baik itu melalui lisan ataupun tulisan. Kata baku dalam bahasa Indonesia ini juga memiliki ciri-ciri sebagai berikut. Pertama, baik secara lisan maupun tulisan, kata baku digunakan dalam situasi resmi, seperti surat menyurat dinas, perundang-undangan, karangan ilmiah, laporan penelitian dan lainnya. Ragam bahasa baku tidak diwarnai atau dicampuri oleh dialek atau logat tertentu. Kedua, baik secara lisan maupun tulisan, kata baku menggunakan ketentuan-ketentuan yang berlaku dalam Pedoman Umum Ejaan Bahasa Indonesia. Ketiga, baik secara lisan maupun tulisan, ragam baku memenuhi fungsi gramatikal seperti subjek, predikat, dan objek secara eksplisit dan lengkap (Sugihastuti \& Siti Saudah, 2018:17-18). Bedasarkan definisi-definisi di atas dapat disimpulkan bahwa kata 
baku adalah kata-kata yang lazim digunakan dalam situasi formal atau resmi yang penulisannya sesuai dengan kaidah-kaidah yang dibakukan. Baku tidaknya sebuah kata dapat dilihat dari segi lafal, ejaan, gramatika, dan kenasionalan saat diucapkan atau ditulis (Chaer, 2011:131).

Suatu kata bisa disebut dengan kata tidak baku bila kata yang dipakai tidak sesuai dengan kaidah bahasa Indonesia. Ketidakbakuan suatu kata bukan hanya diakibatkan oleh salah penulisan saja, akan tetapi dapat juga disebabkan oleh pengucapan yang salah dan penyusunan suatu kalimat yang tidak benar. Kata tidak baku ini sering kali muncul dalam kehidupan kita sehari-hari.

\section{FUNGSI KATA BAKU DALAM BAHASA INDONESIA}

Kata baku dalam bahasa Indonesia mendukung empat fungsi. Tiga diantaranya bersifat pelambang atau simbolis, sedangkan yang satu bersifat objektif. Fungsi-fungsi itu ialah (1) fungsi pemersatu, (2) fungsi pemberi kekhasan, (3) fungsi pembawa kewibawaan, dan (4) fungsi kerangka acuan (Sugihastuti \& Siti Saudah, 2018:18). Kata baku sebagai pemersatu artinya mempersatukan penutur atau penulisnya menjadi satu masyarakat bahasa. Dapat dikatakan juga bahwa pemakaian kata baku dalam bahasa Indonesia dapat mempersatukan sekelompok orang menjadi satu kesatuan masyarakat. Kata baku sebagai pemberi kekhasan artinya pembakuan kata dalam bahasa dapat menjadi pembeda dengan masyarakat pemakai bahasa lainnya.

Kata baku sebagai pembawa kewibawaan artinya kata baku yang diterapkan dalam bahasa dapat memperlihatkan kewibawaan pemakainya. Ahli bahasa dan beberapa kalangan di Indonesia pada umumnya berpendapat bahwa perkembangan bahasa Indonesia dapat dijadikan teladan bagi bangsa lain di Asia Tenggara (dan mungkin juga Afrika) yang juga memerlukan bahasa yang modern. Dapat juga dikatakan bahwa fungsi pembawa kewibawaan ini beralih dari pemilikan bahasa baku yang nyata ke pemilikan bahasa yang berpotensi menjadi bahasa baku. Walaupun begitu, menurut pengalaman, sudah dapat disaksikan di beberapa tempat bahwa penutur yang mahir berbahasa Indonesia "dengan baik dan benar" memperoleh wibawa di mata orang lain (Supriadin, 2016:5). Kata baku sebagai kerangka acuan artinya kata baku menjadi patokan bagi benar atau tidaknya pemakaian bahasa seseorang atau kelompok.

\section{PENGGUNAAN KATA BAKU DAN TIDAK BAKU DI KALANGAN MAHASISWA}

Pada artikel kali ini Penulis menggunakan responden mahasiswa Universitas Pembangunan Nasional "Veteran" Yogyakarta khususnya Prodi Ekonomi Pembangunan tahun ajaran 2019/2020 yang terdiri dari empat kelas mulai dari kelas Ekonomi Pembangunan A sampai Ekonomi Pembangunan D yang berjumlah 140 orang. Penulis mengambil responden dengan kuantitas sama yaitu dua orang untuk setiap kelas. Oleh karena itu, responden yang Penulis gunakan berjumlah 8 
orang. Dalam angket yang Penulis sebarkan kepada responden, ada 15 kata baku dan tidak baku yang disusun secara acak yaitu kata azas, berpikir, cinderamata, diagnosa, dipersilakan, hembus, hakekat, indera, karir, komplit, kreativitas, kyai, materai, nafas dan sekedar. Berdasarkan angket yang sudah diberikan kepada responden, dihasilkan data sebagai berikut:

\begin{tabular}{l|c|c}
\hline \multirow{2}{*}{ Kata } & \multicolumn{2}{|c}{ Responden yang menjawab } \\
\cline { 2 - 3 } & Baku & Tidak Baku \\
\hline Azas & 2 orang & 6 orang \\
\hline Berpikir & 6 orang & 2 orang \\
\hline Cinderamata & 5 orang & 3 orang \\
\hline Diagnosa & 2 orang & 6 orang \\
\hline Dipersilakan & 6 orang & 2 orang \\
\hline Hembus & 4 orang & 4 orang \\
\hline Hakekat & 3 orang & 5 orang \\
\hline Indera & 3 orang & 5 orang \\
\hline Karir & 2 orang & 6 orang \\
\hline Komplit & 4 orang & 4 orang \\
\hline Kreativitas & 1 orang & 7 orang \\
\hline Kyai & 5 orang & 3 orang \\
\hline Materai & 6 orang & 2 orang \\
\hline Nafas & 2 orang & 6 orang \\
\hline Sekedar & 1 orang & 7 orang \\
\hline
\end{tabular}

Hasil angket yang telah disebarkan kepada 8 responden mahasiswa Universitas Pembangunan Nasional "Veteran" Yogyakarta menunjukkan bahwa pemahaman mahasiswa untuk kata baku dan tidak baku masih rendah. Hal ini karena dari 15 kata yang ada pada angket tersebut, hanya ada empat kata baku yaitu kata berpikir, dipersilakan, indera, dan kreativitas. Selain empat kata tersebut, semuanya adalah kata tidak baku. Mahasiswa berpikir bahwa apa yang menurutnya kata baku adalah apa yang sesuai dengan yang mereka ucapkan atau yang mereka ketahui dalam kehidupan sehari-hari. Hal ini menunjukkan bahwa bahasa Indonesia yang baku serta baik dan benar sudah mulai hilang. Hilangnya penggunaan kata baku dalam bahasa Indonesia ini disebabkan oleh masuknya bahasa-bahasa asing yang dicampuradukkan dengan bahasa Indonesia atau sekarang ini lebih dikenal dengan bahasa gaul.

Seiring dengan perkembangan zaman khususnya di Negara Indonesia semakin terlihat jelas pengaruh yang diberikan oleh bahasa gaul terhadap bahasa Indonesia dalam penggunaan tata bahasanya. Penggunaan bahasa gaul yang semakin marak digunakan oleh masyarakat luas menimbulkan dampak negatif terhadap perkembangan bahasa Indonesia sebagai identitas bangsa pada saat sekarang dan masa yang akan datang. Keberadaan bahasa gaul yang masuk dalam tatanan bahasa Indonesia ini tanpa disadari akan menggeser posisi bahasa 
Indonesia sebagai bahasa nasional. Dewasa ini, masyarakat sudah banyak yang memakai bahasa gaul dan parahnya lagi generasi muda Indonesia juga tidak terlepas dari pemakaian bahasa gaul ini. Bahkan generasi muda inilah yang banyak memakai bahasa gaul daripada pemakaian bahasa Indonesia. Generasi muda saat ini menganggap bahwa memakai bahasa gaul lebih terlihat keren dan sesuai dengan usia mereka dibandingkan memakai bahasa Indonesia yang baik dan benar yang dirasa terlalu formal dalam kehidupan sehari-hari. Untuk menghindari pemakaian bahasa gaul yang sangat luas di masyarakat, seharusnya kita menanamkan kecintaan dalam diri generasi bangsa terhadap bahasa Indonesia sebagai bahasa nasional (Rahayu, Arum Putri, 2015:5). Mahasiswa sebagai generasi muda yang nantinya menjadi agen perubahan bangsa Indonesia harusnya selalu menggunakan bahasa Indonesia yang baku, baik, dan benar. Kata-kata yang ada pada angket tersebut hanyalah sedikit gambaran kata-kata yang sering kita dengar dan kita gunakan dalam kehidupan sehari-hari. Namun kenyataannya masih banyak mahasiswa yang tidak memahami penulisan yang baku dari katakata tersebut. Padahal mahasiswa adalah orang yang sudah berpendidikan dan dianggap pengetahuannya melebihi siswa SMP, SMA, maupun masyarakat pada umumnya.

\section{SIMPULAN}

Berdasarkan hal yang sudah dipaparkan diatas, dapat disimpulkan bahwa kata baku adalah kata-kata yang sesuai atau terdapat dalam Kamus Besar Bahasa Indonesia. Kata baku ini memiliki berbagai fungsi seperti pemersatu, pemberi kekhasan, pembawa kewibawaan, serta sebagai kerangka acuan. Kata baku dalam bahasa Indonesia membuat bahasa Indonesia menjadi kuat kedudukannya karena kata baku tidak mengubah struktur bahasa Indonesia sehingga mudah dijadikan alat komunikasi antar masyarakat atau antar suku di Indonesia. Akan tetapi, mahasiswa yang sering menggunakan bahasa Indonesia sebagai alat komunikasi malah kurang pengetahuan tentang kata baku sebagai dasar bahasa Indonesia yang baik dan benar.

\section{DAFTAR PUSTAKA}

Chaer, Abdul. 2011. Kesantunan Bebahasa. Jakarta: Rineka Cipta.

Kosasih, E. dan Hermawan , Wawan. 2012. Bahasa Indonesia Berbasis Kepenulisan Karya Ilmiah dan Jurnal. Bandung: Thursina.

Rahayu, Arum Putri. 2015. "Menumbuhkan Bahasa Indonesia yang Baik dan Benar dalam Pendidikan dan Pengajaran". Dalam Jurnal: Paradigma, Volume 2, Nomor 1, Halaman 1-15.

Setiawati, Sulis. 2016. "Penggunaan Kamus Besar Bahasa Indonesia (KBBI) dalam Pembelajaran Kosakata Baku dan Tidak Baku Pada Siswa Kelas IV SD". Dalam Jurnal: Gramatika, Volume 2, Nomor 1, Halaman 44-51. 
Sugihastuti, Siti Saudah. 2015. Buku Ajar Bahasa Indonesia Akademik. Yogyakarta: Pustaka Pelajar.

Supriadin. 2016. “Identifikasi Penggunaan Kosakata Baku dalam Wacana Bahasa Indonesia pada Siswa Kelas VII di SMP Negeri 1 Wera Kabupaten Bima Tahun Pelajaran 2013/2014". Jurnal: Ilmiah Mandala Education, Volume 2, Nomor 2, Halaman $1-12$. 